\title{
5 Research Square \\ Factors associated with postpartum psychiatric disorders using routine administrative data
}

Flávia Jôse Oliveira Alves ( $\square$ flaviajosy1@gmail.com )

FIOCRUZ Bahia: Instituto Goncalo Moniz https://orcid.org/0000-0003-1613-2270

Luis F. Castro-de-Araujo

FIOCRUZ Bahia: Instituto Goncalo Moniz

\section{Erika Fialho Morais Xavier}

FIOCRUZ Bahia: Instituto Goncalo Moniz

Vivian Alessandra Ferreira da Silva

FIOCRUZ Bahia: Instituto Goncalo Moniz

Daiane Borges Machado

FIOCRUZ Bahia: Instituto Goncalo Moniz

Maurício L. Barreto

FIOCRUZ Bahia: Instituto Goncalo Moniz

\section{Research Article}

Keywords: Postpartum depression, risk factors, Brazil, Public Mental Health

Posted Date: February 23rd, 2022

DOI: https://doi.org/10.21203/rs.3.rs-1256792/v1

License: (c) (i) This work is licensed under a Creative Commons Attribution 4.0 International License. Read Full License

Version of Record: A version of this preprint was published at International Journal of Population Data Science on March 1st, 2022. See the published version at https://doi.org/10.23889/ijpds.v7i2.1738. 


\section{Abstract}

Objective: To evaluate factors associated with postpartum psychiatric disorders and to propose a new approach for the use of routine mental health service data in Brazil

Methods: We extracted data on visits to psychiatric outpatient services from the Authorization of Outpatient Procedures in Brazil (2008-2012). Generalized Additive Models for Location, Scale, and Shape (GAMLSS) with double Poisson distribution were performed, with postpartum psychiatric disorders as the dependent variable.

Results: At each increment in the maternal age unit and CAPS coverage percentage, there was an increase of $1.01(p<0.001)$ in the occurrence of postpartum psychiatric disorders.

Conclusions: An increase in age is associated with a higher risk of presenting a postpartum psychiatric disorder. This approach provides an innovative feature to routinely analyse collected data.

\section{Background}

The burden of postpartum psychiatric disorders is an important public health issue, affecting the mother's health and child's development. It is estimated that $10-15 \%$ of women are affected by postpartum depression, with depressive symptoms occurring during the first four weeks after birth, and usually lasting for more than 6 months ${ }^{1,2}$. The prevalence of postpartum psychiatric disorders in low- and middle-income countries appears to be higher than in developed countries, with almost $20 \%$ of women experiencing mental health disorders following childbirth $1,2,3,4$.

Among the factors associated with postpartum psychiatric disorders are less education and a low socioeconomic level, a lack of social support, a history of mental disorders, antenatal depression, maternal age extremes, unintended pregnancies, and marital problems ${ }^{4,5,6,7}$. Postpartum psychiatric disorders have adverse short- and long-term effects on women's health, impacting maternal morbidity and the quality of life ${ }^{6}$.

Despite their importance and consequences, postpartum psychiatric disorders are still under-investigated. Most studies have been conducted in highly developed countries ${ }^{1}$. In Brazil, research is restricted to state capitals and is not representative of the country as a whole $e^{8,9}$. Understanding the factors associated with postpartum psychiatric disorders can provide insights for adequate mental health screening during the prenatal and postpartum periods. Taking this into consideration, this study was conducted with the objective of evaluating factors associated with postpartum psychiatric disorders. The research also presents an approach to neutralizing the bias from repeated observations due to use of routine mental health service data in Brazil,.

\section{Methods}


We used Authorization of Outpatient Procedure (Autorização de Procedimentos Ambulatoriais - APAC) data for women aged between 19 and 59 who used community mental health services in Brazil between 2008 and 2012. All of the data was processed, anonymized, and provided by DATASUS (www2.datasus.gov.br). APAC information was taken from the file transfer option service area. Data was retrieved from AD-APAC reports (AD-APAC de laudos diversos), which are part of the Outpatient Information System (SIASUS).

The dependent variable was diagnosis of mental disorders and behavioural factors associated with the puerperium (ICD-10 code F53). We also analysed the occurrence of postpartum psychiatric disorders for each ICD-10 category: F53.0 (mild mental and behavioural disorders associated with the puerperium); F53.1 (severe mental and behavioural disorders associated with the puerperium); F53.8 and F53.9 (other mental and behavioural disorders associated with the puerperium, and non-specified mental and behavioural disorders associated with the puerperium, respectively). The following covariates were considered for the analysis: age categorized in quartiles (19-25, 26-30, 31-35, 36-40, and > 40 years), Psychosocial Care Centre (CAPS) coverage (number of CAPS in each municipality per 100,000 inhabitants, based on the type of CAPS). The formula used for this indicator was: [(No. CAPS I x 0.5) + $($ No. CAPS II) + (No. CAPS III x 1.5) + (No. CAPSi $)+($ No. CAPSad $)] /$ Population $\times 100,000 .{ }^{10}$ The CAPS type is specified in the supplementary material (Box 1$)$.

The data analysed comprised information on outpatient visits and the non-individual diagnosis of mental disorders, which is made available and anonymized by the Brazilian government. Therefore, the data set includes the repetition of subjects who utilized outpatient services. In order to partially neutralize the bias from repeated observations, we applied a method commonly used in population genetics, consisting of extracting the geographic information for each visit to the level of the patient's neighbourhood. This was then recoded in latitude and longitude using the $\mathrm{R}$ package, CepR version 0.1.2 ${ }^{11}$ and incorporated with age in a confirmatory factor analysis, using the UMX R package, version 4.9.0 ${ }^{12,13}$. A latent variable was specified and a score per observation generated, which we called the proximity index (PP). This was performed in such a way that two lines with very similar addresses and ages showed scores that are close together. Therefore if they are added to the model, it penalizes the model for the individuals' proximity, and achieves a more realistic estimate of the relationships under analysis.

In order to investigate the factors associated with mental and behavioural disorders associated with the puerperium, we used Generalized Additive Models for Location, Scale, and Shape (GAMLSS) with double Poisson distribution, and all ICD code F53 records as the outcome variable.

Data management, import, and analyses were all performed in R, version 4.1.1 (https://cran.rproject.org/). Since all of the data had previously been anonymized and made public by the Brazilian Ministry of Health, ethical approval was not required.

\section{Results}


A total of 6,802 records of mental and behavioural disorders associated with the puerperium diagnoses were identified in this study. The proportion of outpatient visits of women aged under 35 in the sample was $68.05 \%$. The majority of the records were for women in the 31 to 35 year old group $(25.43 \%)$ (Supplementary Figure 1). With regards to Brazilian regions, the Northeast had the highest number of outpatient visits (62.14\%), followed by the Southeast (20.15\%) (Supplementary Table 1 ). CAPS coverage presented the highest mean coverage in the Northeast $(1.92 \%)$ and the lowest in the Central-West $(0.92 \%)$ (Supplementary Table 1).

With regards to the severity of postpartum psychiatric disorders, $47.6 \%$ of outpatient visit records were for diagnosis of ICD F53.1, and 32.09\% for ICD-10 F53.0, which correspond to severe and mild mental disorders associated with the puerperium, respectively (Supplementary Table 2). Diagnosis for ICD-10 F53.0 was higher between the ages of 26 and 30 (10\%), while diagnosis for ICD F53.1 was higher between the ages of 31 and 35 (12.7\%) (Supplementary Table 2).

Our multivariate regression model showed that for each increment in the maternal age unit and CAPS coverage percentage, there is an increase of $1.01(p<0.001)$ in the occurrence of postpartum psychiatric disorders (Figure 1).

\section{Discussion}

Our results showed that increases in maternal age and municipal CAPS coverage also heightened the risk of postpartum psychiatric disorders. With regards to severity, we found that diagnosis for ICD F53.0 (mild mental and behavioural disorders associated with the puerperium) was higher among women aged between 26 and 30, while diagnosis for ICD F53.1(severe mental and behavioural disorders associated with the puerperium) was higher among women aged between 31 and 35 .

Previous studies have demonstrated higher risks for postpartum mental disorders concentrated in age extremes $^{14,15,16}$. Our results are similar to previous Brazilian studies reporting advanced maternal age as a risk factor for postpartum mental disorders ${ }^{8,9}$. Postpartum depression is a multifactorial phenomenon, with socioeconomic and demographic factors, and access to health services involved with its occurrence $e^{4,5,6,7}$.

The risk factors differ depending on the women's life cycle $^{17}$. Isolation and social support are important predictors of postpartum depression among adolescent women, ${ }^{17,18}$ while race, unintended pregnancy and socioeconomic status have an increased influence among adult women ${ }^{17}$. On the other hand, it is known that adolescent women tend to use health services less than older women, and this could potentially influence the recording of information by age group $18,19,20,21,22$.

CAPS coverage was associated with a higher number of postpartum mental disorder records in our study. CAPS are reference services for the most severe cases, also influencing the identification of cases, with adequate diagnosis and the subsequent generation of APAC records ${ }^{23,24,25,26}$. With psychiatric reform in 
Brazil, CAPS were established to replace psychiatric hospitals, assuming the characteristics of alternative services, and organization of the public mental health network ${ }^{10}$, with expansion of these community services over the years ${ }^{23,24}$. By increasing provision in this way, the demand for these services also increases ${ }^{23}$.

This study represented an attempt to examine the factors associated with mental and behavioural disorders associated with puerperium in Brazilian women using national register data. Routine deidentified administrative data provides the possibility to explore an association which has not yet been fully investigated. We were able to control for possible duplications and explore factors that may influence the occurrence of postpartum mental disorders with great accuracy through the proximity index (PP).

To the best of our knowledge, this is the first study to explore puerperal mental disorders based on routine mental health data throughout Brazil. The proposed approach provides an innovative feature through the proximity index (PP), to control for duplications and improve information, to develop public health actions. Since this data derives from an anonymized database (APAC), we were not able to distinguish between information on a new or returning individual. Although the conclusions are not intended to be causal, the results presented in this study reinforce the need to consider data quality and taking the management of duplications into account as a preliminary step in routine dataset analyses. The use of these datasets is a valuable and much needed resource for future mental health studies.

\section{Conclusions}

Our findings support the need to improve knowledge of maternal mental health and to integrate routine screening into postnatal care settings, for the early identification of women who are at risk of developing puerperal mental disorders, and to apply timely preventive and therapeutic approaches.

\section{Abbreviations}

APAC

Authorization of Outpatient Procedure (Autorização de Procedimentos Ambulatoriais

CAPS

Psychosocial Care Centre

GAMLSS

Generalized Additive Models for Location, Scale, and Shape

PP

Proximity Index

\section{Declarations}

Ethics approval and consent to participate 
The study was conducted according to the guidelines laid down in the Declaration of Helsinki. As the study exclusively used publicly available de-identified data, ethics approval by a research ethics committee and informed consent are waived per Resolution n. 466/2012 of the National Health 100 Council of Brazil's Commission of Ethics in Research.

\section{Consent to publish}

No applicable

\section{Availability of data and materials}

The data used are public and available from the Brazilian Ministry Health (DATASUS) website: http://www2.datasus.gov.br/DATASUS/index.php

\section{Competing interests}

The authors declare that they have no competing interests.

\section{Funding}

This study was funded by Medical Research Council - UK MR/T03355X/1

\section{Authors' contributions}

LFCA, VAFS and FJOA contributed to conceptualizing the study. LFCA supervised all aspects of study implementation and data collection. LFCA and EFMX performed the statistical analyses. FJOA drafted the manuscript. LFCA, EFMX, DBM and MLB provided substantial edits and revisions. All authors have read the final version of the manuscript and approved of the decision to submit for publication.

\section{Acknowledgements}

No applicable

\section{References}

1. Alshikh Ahmad H, Alkhatib A, Luo J. Prevalence and risk factors of postpartum depression in the Middle East: a systematic review and meta-analysis. BMC Pregnancy Childbirth. 2021;21:542. https://doi.org/10.1186/s12884-021-04016-9.

2. Wolf A, De Andraca I, Lozoff B. Maternal depression in three Latin American samples. Soc Psychiatry Psychiatr Epidemiol. 2002;37:169-76. https://doi.org/10.1007/s001270200011.

3. Stewart DE, et al. "Postpartum depression: Literature review of risk factors and interventions."

Toronto: University Health Network Women's Health Program for Toronto Public Health (2003): 1289.

4. Fisher $\mathrm{J}$, et al. Prevalence and determinants of common perinatal mental disorders in women in lowand lower-middle-income countries: a systematic review. Bull World Health Organ. 2012;90:139-49. 
5. Rai S, Pathak A, Sharma I. Postpartum psychiatric disorders: Early diagnosis and management. Indian journal of psychiatry. 2015;57 Suppl 2:216.

6. Slomian J, et al. Consequences of maternal postpartum depression: A systematic review of maternal and infant outcomes. Women's Health. 2019;15:1745506519844044.

7. Ghaedrahmati M, Kazemi A, Kheirabadi G, Ebrahimi A, Bahrami M. Postpartum depression risk factors: A narrative review. J Educ Health Promot. 2017 Aug 9;6:60. doi: 10.4103/jehp.jehp_9_16. PMID: 28852652; PMCID: PMC5561681.

8. Lobato G, et al. Postpartum depression according to time frames and sub-groups: a survey in primary health care settings in Rio de Janeiro, Brazil. Arch Women Ment Health. 2011;14:187-93. 3 ).

9. Cantilino A, et al. Postpartum depression in Recife-Brazil: prevalence and association with bio-sociodemographic factors. Jornal Brasileiro de Psiquiatria. 2010;59(1):1-9.

10. Brasil. Ministério da Saúde.Portaria $n^{\circ} 2.669$, de 3 de novembro de 2009. Estabelece as prioridades, objetivos, metas e indicadores de monitoramento e avaliação do Pacto pela Saúde, noscomponentes pela Vida e de Gestão, e as orientações, prazos e diretrizes do seuprocesso de pactuação para o biênio 2010- 2011.(2009).

11. Robert Myles McDonnell. (2020). cepR: Busca CEPs Brasileiros. R package version 0.1.2. https://CRAN.R-project.org/package=cepR.

12. Timothy C, Bates MC, Neale HH, Maes. (2019). umx: A library for Structural Equation and Twin Modelling in R. Twin Research and Human Genetics, 22, 27-41. DOI:10.1017/thg.2019.2.

13. Timothy C. Bates._umx: A helper package for Structural Equation Modeling in OpenMx_. Edinburgh: University of Edinburgh; 2021.

14. 5281/zenodo.10937 (URL. https://doi.org/10.5281/zenodo.10937),version 2.10.0, <URL: https://github.com/tbates/umx/>.

15. Alharbi AA, Abdulghani HM. Risk factors associated with postpartum depression in the Saudi population. Neuropsychiatr Dis Treat. 2014:10:311-6.

16. Bjerke SE, Vangen S, Nordhagen R, Yiterdahl T, Magnus P, Stray Pedersen B. Postpartum depression among Pakistani women in Norway: prevalence and risk factors. J Matern Fetal Neonatal Med. 2008;21(12):889-94.

17. Wolff A, De-Andraca I, Lozoff B. Maternal depression in three Latin American samples. Soc Psychiatry Psychiatr Epidemiol. 2002;37(4):169-76.

18. Nunes AP, Phipps MG. Postpartum depression in adolescent and adult mothers: comparing prenatal risk factors and predictive models. Matern Child Health J. 2013 Aug;17(6):1071-9. doi: 10.1007/s10995-012-1089-5. PMID: 22886352.

19. Yozwiak JA. Postpartum depression and adolescent mothers: a review of assessment and treatment approaches. J Pediatr Adolesc Gynecol. 2010 Jun;23(3):172-8. doi: 10.1016/j.jpag.2009.09.003. PMID: 20496498. 
20. Anderson JK, et al. "A scoping literature review of service-level barriers for access and engagement with mental health services for children and young people." (2017).

21. Carvacho I, Espejo, et al. Fatores associados ao acesso anterior à gestação a serviços de saúde por adolescentes gestantes. Revista de Saúde Pública. 2008;42:886-94.

22. Martins $\mathrm{MM}$, Flores, et al. Acesso aos serviços de atenção primária à saúde por adolescentes e jovens em um município do Estado da Bahia, Brasil. Cadernos de Saúde Pública. 2019;35:e00044718.

23. Nunes BP, Flores TR, Duro SMS, Saes MO, Tomasi E, Santiago AD, et al. Utilização dos serviços de saúde por adolescentes: estudo transversal de base populacional, Pelotas-RS, 2012. Epidemiol Serv Saúde. 2015;24:411-20.

24. Onocko-Campos. Rosana Teresa. "Saúde mental no Brasil: avanços, retrocessos e desafios. Cadernos de Saúde Pública. 2019;35:e00156119.

25. Brazil. Ministry of Health. Mental health data. Secretaria de Atenção à Saúde. Departamento de Ações Programáticas e Estratégicas. Coordenação Geral de Saúde Mental: Ministry of Health; 2007.

26. Brazil. Ministry of Health. Secretaria de Gestão Estratégica e Participativa. Departamento de Articulação Interfederativa. Objetivos: Caderno de diretrizes; 2013. pp. 2013-5.

27. Brazil. Departamento de Ações Programáticas Estratégicas. (2004). SUS Mental health: psychosocial care centres. Ministry of Health.

\section{Figures}




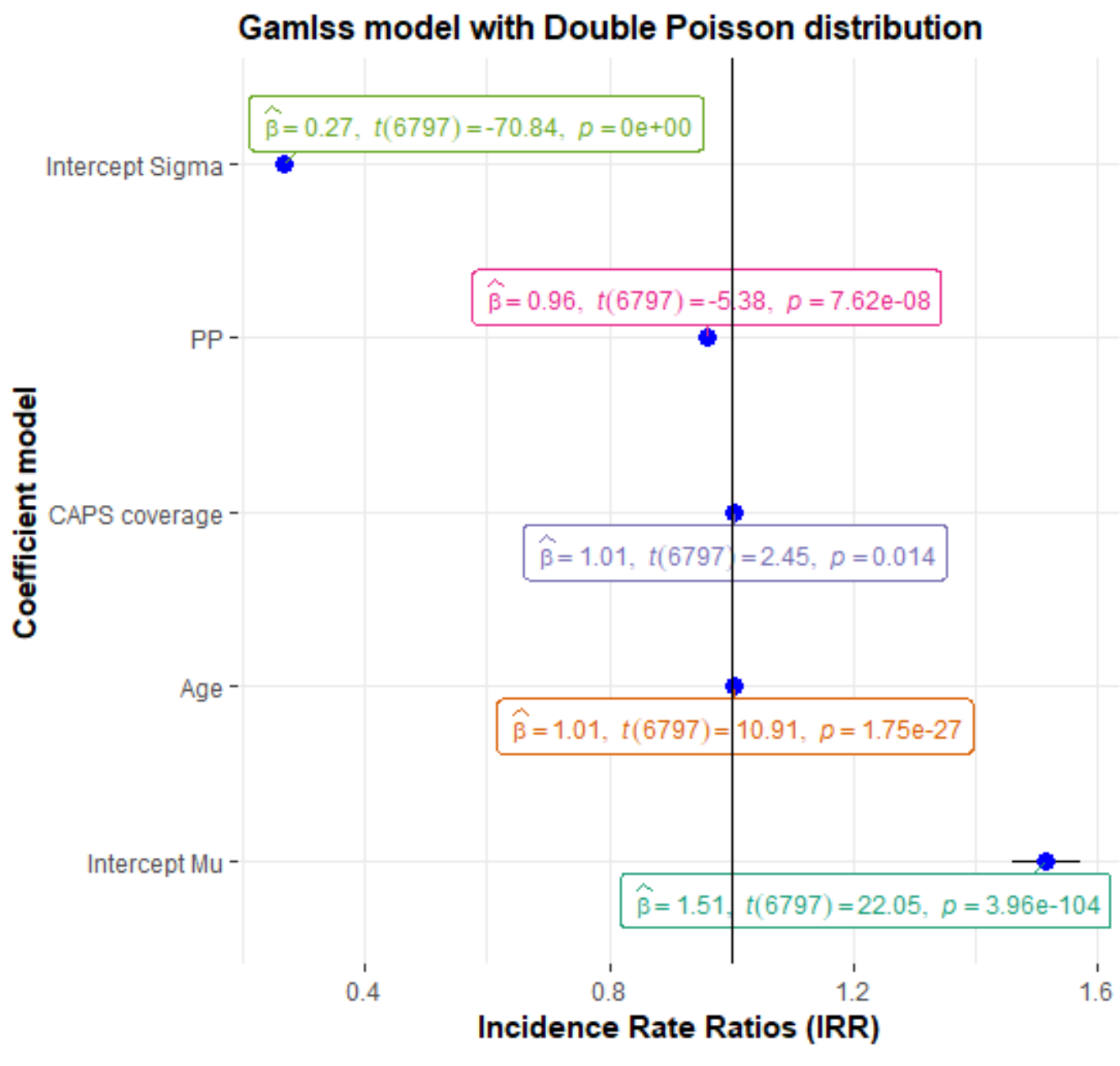

$\mathrm{AIC}=14276, \mathrm{BIC}=14310$

\section{Figure 1}

Estimates of model parameters, incidence rate ratios (IRR) and p-values for the association between CAPS coverage, age, the proximity index (PP) and postpartum psychiatric disorders.

\section{Supplementary Files}

This is a list of supplementary files associated with this preprint. Click to download.

- SuplementmaterialPuerperium02122021.doc 